Laser Chem.

Volume 1(5), May 1983, pp. 195-209

0278-6273/83/0105-0195\$12.00/0

(C) 1983 harwood academic publishers gmbh

Printed in Great Britain

\title{
New Continuous Laser Emissions in $\mathrm{Te}_{2}$
}

\author{
A. TOPOUZKHANIAN* ${ }^{*}$ B. WELLEGEHAUSEN**, C. EFFANTIN* ${ }^{*}$, J. d$^{\prime}$ INCAN $^{*}$ \\ and J. VERGES ${ }^{\star \star *}$ \\ "Laboratoire de Spectrométrie lonique et Moléculaire, Université Claude \\ Bernard (Lyon I), 69622 Villeurbanne Cedex, France; **Institut für \\ Quantenoptik, Universität Hannover, 3000 Hannover 1, Federal Republic of \\ Germany; ***Laboratoire Aimé Cotton, CNRS II, 91405 Orsay, France
}

(Received October 15, 1982; in final form December 3, 1982)

New continuous laser emissions of different $\mathrm{Te}_{2}$ isotopes on many lines in the spectral range of $4600 \AA$ to $7800 \AA$ have been obtained upon excitation with the $4067 \AA$ and $4131 \AA$ lines of a krypton ion laser. Thresholds of several $\mathrm{mW}$ and output efficiencies of $5 \%$ have been achieved. By means of Fourier transform spectrometry accurate fluorescence wavenumbers have been determined, leading to an exact assignment of the observed laser lines.

\section{INTRODUCTION}

Optically pumped dimer laser investigations performed for some time have succeeded in many new systems covering extended spectral regions. ${ }^{1}$ There is presently some interest in the development of new systems that can be excited with available pulsed or cw UV lasers and have emissions in the blue-green or even throughout the whole visible spectral range. Especially $\mathrm{S}_{2}$ dimers have gained some attention as a laser system with possible high conversion efficiencies and output powers when being excited with powerful excimer lasers. ${ }^{2}$ This system also offers some chances for discharge assisted or eventually even pure discharge pumped operation. ${ }^{3}$ However, as a pure optically pumped system, $S_{2}$ has some disadvantages as high temperatures are necessary to break the normally present polymers into 
dimers. ${ }^{1}$ Further interesting candidates for the considered spectral range are the other group VI dimers as $\mathrm{Se}_{2}$ and $\mathrm{Te}_{2}$ which require much lower temperatures. Continuous laser oscillation of $\mathrm{Se}_{2}$ excited at $3511 \AA$ with an argon ion laser and with laser emission in the range of $3870 \AA$ to 7090 $\AA$ has been reported recently. ${ }^{4}$ Laser operation of $\mathrm{Te}_{2}$ excited with some blue argon laser lines and emission in the yellow-red spectral range has been obtained earlier. ${ }^{5}$ In this case excitation starts from higher vibrational levels. In order to obtain low operating temperatures and the broadest possible laser emission range, excitation should start from the lowest vibrational level. In the case of $\mathrm{Te}_{2}$ this can be achieved by using the violet krypton laser lines at $4067 \AA$ and $4131 \AA^{6} .^{6}$

In this paper we report on first continuous laser oscillation of ${ }^{130} \mathrm{Te}_{2}$ and several other $\mathrm{Te}_{2}$ isotopes upon excitation with these krypton laser lines. By means of Fourier transform spectrometry the involved pump and laser transitions have been identified and accurate transition wavenumbers of the fluorescence lines corresponding to the observed laser lines are given.

\section{SPECTROSCOPIC DATA}

Fluorescence spectra of ${ }^{130} \mathrm{Te}_{2}$ and ${ }^{128} \mathrm{Te}_{2}$ isotopic molecules, excited by fixed-frequency argon and krypton ion lasers, have been recorded by high resolution Fourier transform spectrometry and their analysis has been reported recently. ${ }^{6}$ In this paper the collisional aspect has only been treated from a spectroscopic point of view. These detailed studies have been especially helpful for the optically pumped laser investigations described here.

Figure 1 gives the potential curves of the $X, B$ and $b$ states. The equilibrium internuclear distance $r_{e}=2.824 \AA$ of the $B$ state is markedly greater than those of the $X$ and $b$ states $(2.5574 \AA$ and $2.5862 \AA$, respectively). This circumstance is particularly favorable to observe many transitions in the fluorescence series, spanning broad spectral ranges. $B-X$ transitions thereby yield emissions throughout the visible spectral region, while the existence of the $b$ state, $9600 \mathrm{~cm}^{-1}$ above the $X 0_{g}^{+}$state, leads to intense fluorescence series in the infrared between $6000 \mathrm{~cm}^{-1}$ and 15000 $\mathrm{cm}^{-1} \cdot{ }^{7}$ The equilibrium molecular constants of ${ }^{130} \mathrm{Te}_{2}$ have been determined with great accuracy ${ }^{6}$ and these data also allow the calculation of the electronic transitions of the combination of isotopes in natural or enriched 


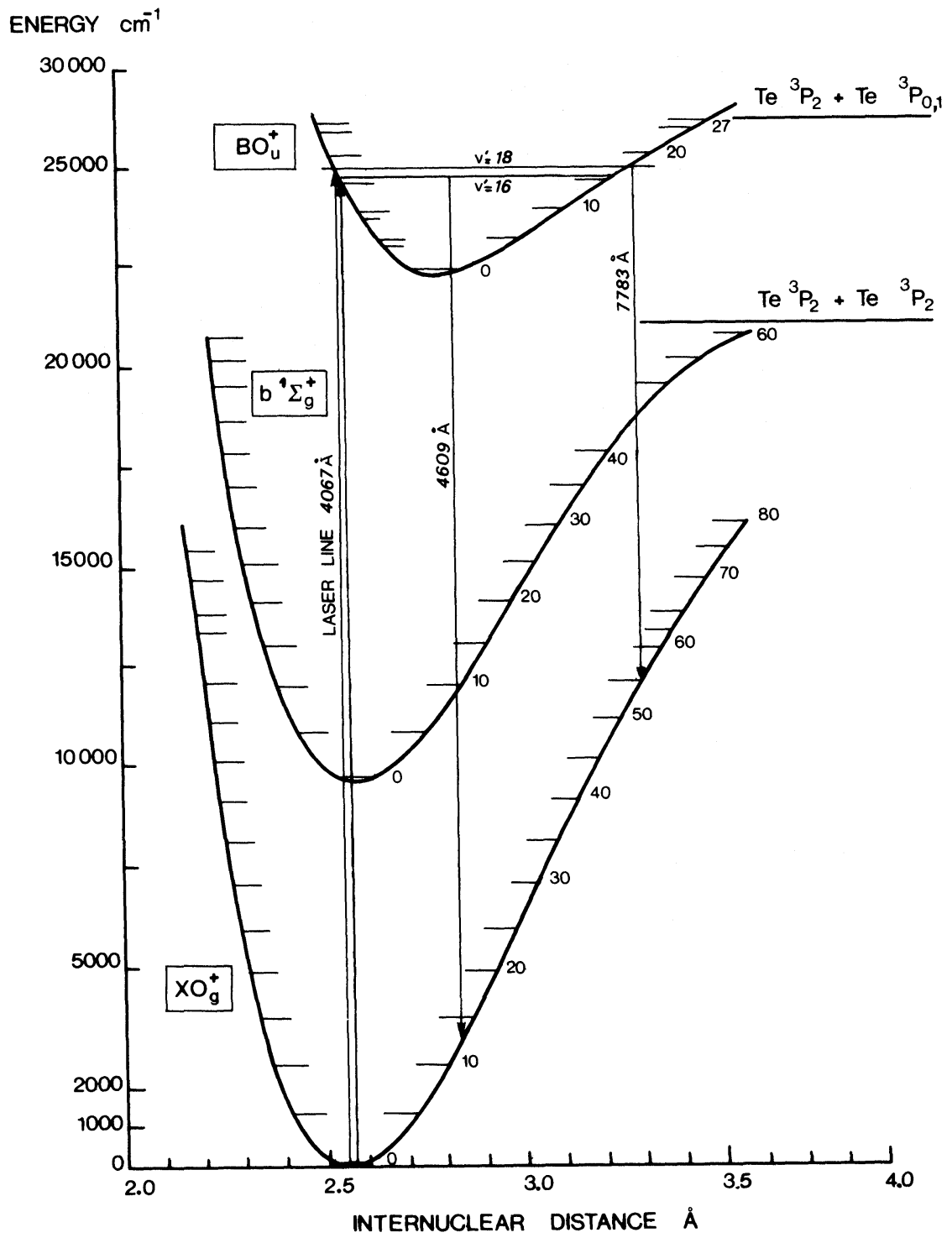

FIGURE 1 Energy level diagram of $\mathrm{Te}_{2}$ (after Ref. 6) with pump and observed laser transitions for ${ }^{130} \mathrm{Te}_{2}$. 
tellurium with an uncertainty of a few mk $\left(0.001 \mathrm{~cm}^{-1}\right)$ and thereby the prediction of further pump and laser lines.

Some of the numerous fluorescence series studied originate in excited levels which are pumped from the most populated $v^{\prime \prime}=0$ level of the fundamental state $X 0_{g}^{+}$. These series consist mainly of $\mathrm{P}, \mathrm{R}$ doublets with spacings ranging between $6 \mathrm{~cm}^{-1}$ and $20 \mathrm{~cm}^{-1}$. The strongest of them are surrounded by satellites corresponding to $\Delta J= \pm 2, \pm 4 \ldots$, which are populated by rotational relaxation. Excitation and fluorescence transitions for different $\mathrm{Te}_{2}$ isotopes, analyzed by Fourier transform spectrometry upon excitation with the $4067 \AA$ and $4131 \AA$ lines of the krypton laser, are summarized in Table I. Low resolution fluorescence spectra of ${ }^{130} \mathrm{Te}_{2}$ and natural $\mathrm{Te}_{2}$ are given in Figures 2 and 3.

\section{LASER INVESTIGATIONS}

For the optically pumped laser experiments a small all-quartz cell described elsewhere ${ }^{4}$ was filled with natural or isotopically pure tellurium and heated to temperatures around $700^{\circ} \mathrm{C}$ and $570^{\circ} \mathrm{C}$ for cell and reservoir respectively. A low-loss linear concentric resonator with mirrors of equal radii (260

TABLE I

Excitation and fluorescence transitions observed for different $\mathrm{Te}_{2}$ isotopes and analyzed by Fourier transform spectrometry

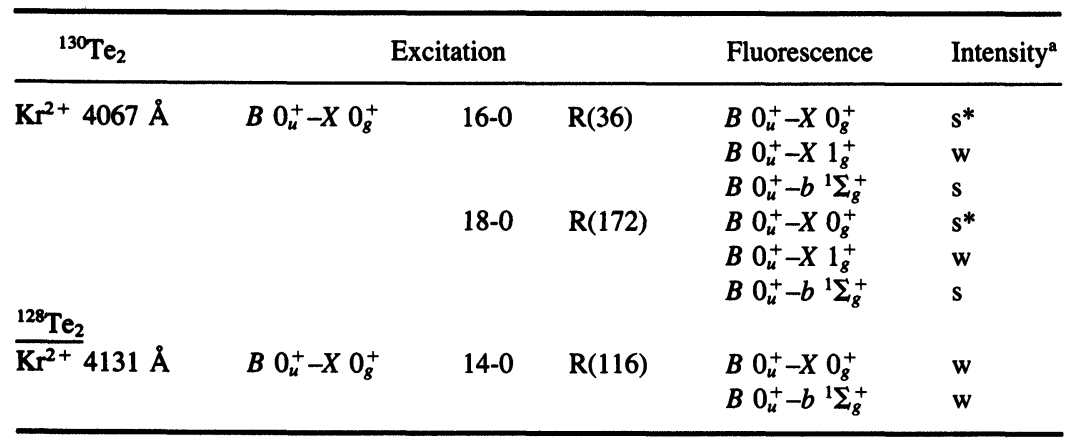

aw: weak, s: strong, with respect to total emission.

*Fluorescence transition showing laser effect. 


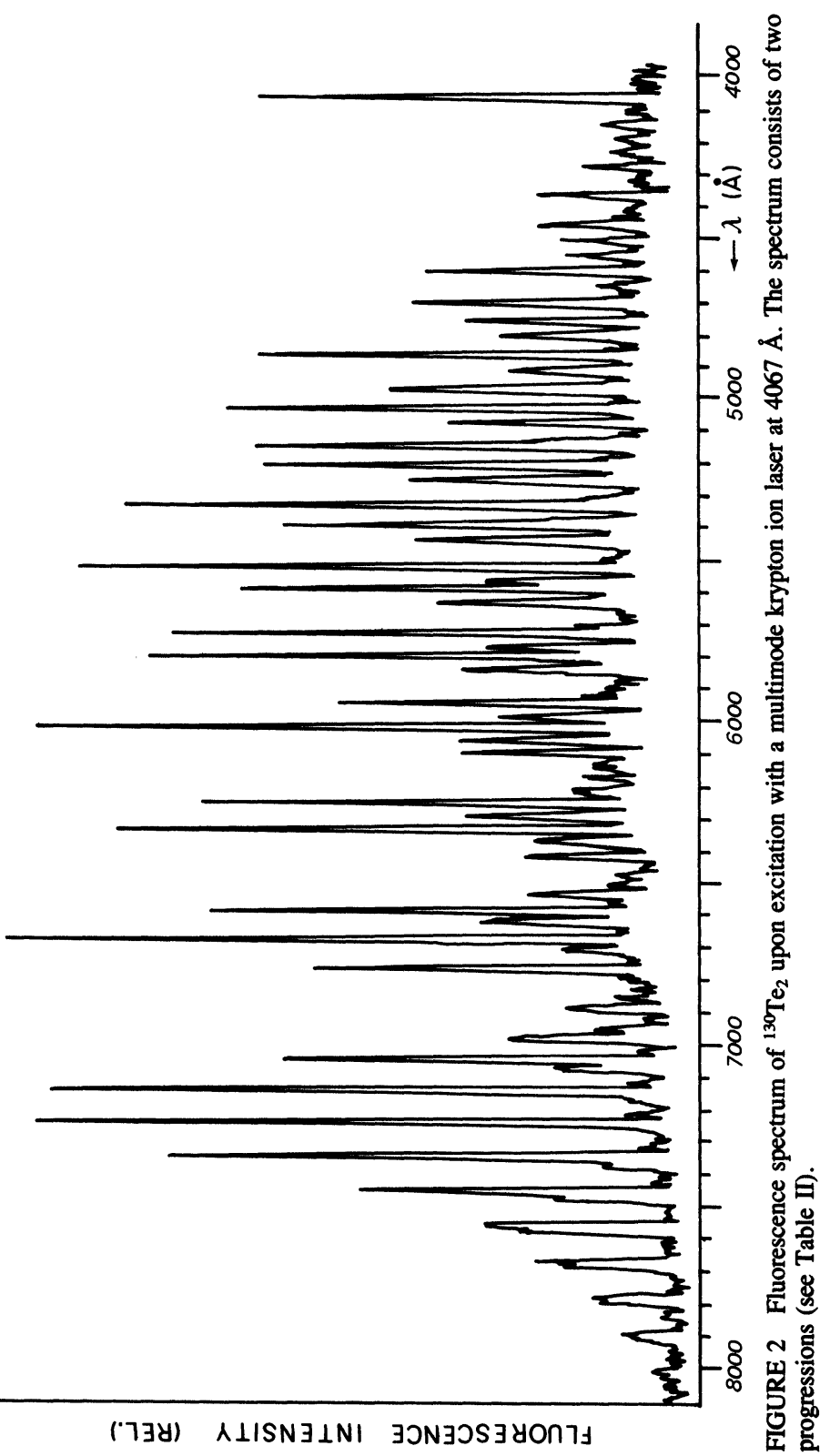




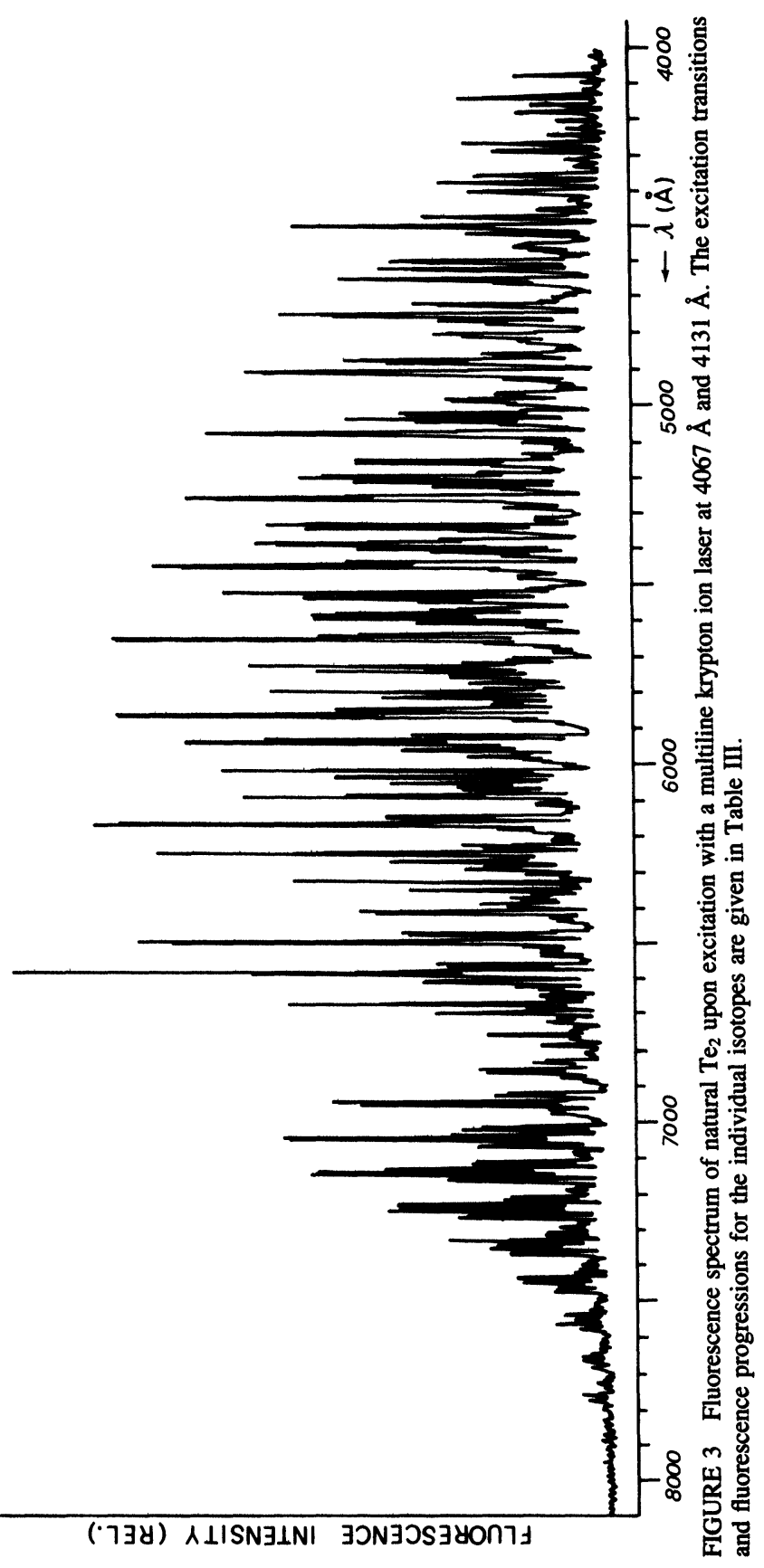


$\mathrm{mm})$ at a distance of roughly $460 \mathrm{~mm}$ was initially used to obtain laser oscillation. The pump was a 15 -watt krypton laser at $4067 \AA$ or $4131 \AA$, or at both wavelengths (multiline operation). Four sets of mirrors with different coatings in the range of about $4000 \AA$ to $8000 \AA$ have been used for the laser experiments. Investigations to obtain laser oscillation in the mentioned infrared spectral range have not been performed so far. For ${ }^{130} \mathrm{Te}_{2}$ continuous laser oscillation excited by the $4067 \AA$ line has been obtained on most of the fluorescence doublets in the spectral range of 4600 $\AA$ to $7800 \AA$ (Figure 2). The laser lines, belonging to two fluorescence series, are given in Table II together with additional spectroscopic data. For wavelengths below $5000 \AA$, laser oscillation is weak and critically depends on the operating conditions. With one set of mirrors, multiline oscillation on more than 20 lines has been observed. With the $4131 \AA$ excitation line, laser oscillation has been obtained as well but much weaker than in the case of the $4067 \AA$ line.

Natural tellurium pumped by both $4067 \AA$ and $4131 \AA$ radiations gives rise to laser oscillation as well. The fluorescence spectrum (Figure 3 ) is extremely dense due to the contribution of different isotopic molecules. Natural Te consists of 8 isotopes with the following abundances ${ }^{8}:{ }^{130} \mathrm{Te}$ : $34.48 \% ;{ }^{128} \mathrm{Te}: 31.79 \% ;{ }^{126} \mathrm{Te}: 18.71 \% ;{ }^{125} \mathrm{Te}: 6.99 \% ;{ }^{124} \mathrm{Te}: 4.61 \% ;{ }^{123} \mathrm{Te}:$ $0.87 \%$; ${ }^{122} \mathrm{Te}: 2.46 \% ;{ }^{120} \mathrm{Te}: 0.089 \%$. With the help of Fourier transform spectrograms it has been possible to establish that four different molecules- ${ }^{130} \mathrm{Te}_{2},{ }^{128} \mathrm{Te}_{2},{ }^{130} \mathrm{Te}^{128} \mathrm{Te}$, and ${ }^{128} \mathrm{Te}^{126} \mathrm{Te}$-give rise to the laser effect (Table III). Some high resolution spectra, recorded in the second order of a $3.4 \mathrm{~m}$ grating spectrograph, showing simultaneous oscillation of different $\mathrm{Te}_{2}$ isotopes are given in Figure 4. It is observed that the doublet lines are mainly of inequal intensity. For natural $\mathrm{Te}_{2}$, laser oscillation has only been investigated in the spectral range of about $5200 \AA$ to $7500 \AA$ without any further optimization (Table IV); but it is believed that oscillation at shorter wavelengths and with higher output powers will also be possible. For ${ }^{130} \mathrm{Te}_{2}$ additional laser data are summarized in Table IV. The search for possible laser lines has been carried out using a linear twoelement resonator with low output coupling. In this case thresholds of a few milliwatts can typically be obtained. For output power investigations and single line operation a linear-folded resonator with a plan end-mirror and an internal prism or interference filter has been used. For the given pump power, a maximum output coupling of about $30 \%$ was possible, which corresponds to a gain coefficient of roughly $0.04 \mathrm{~cm}^{-1}$. The $\mathrm{Te}_{2}$ 


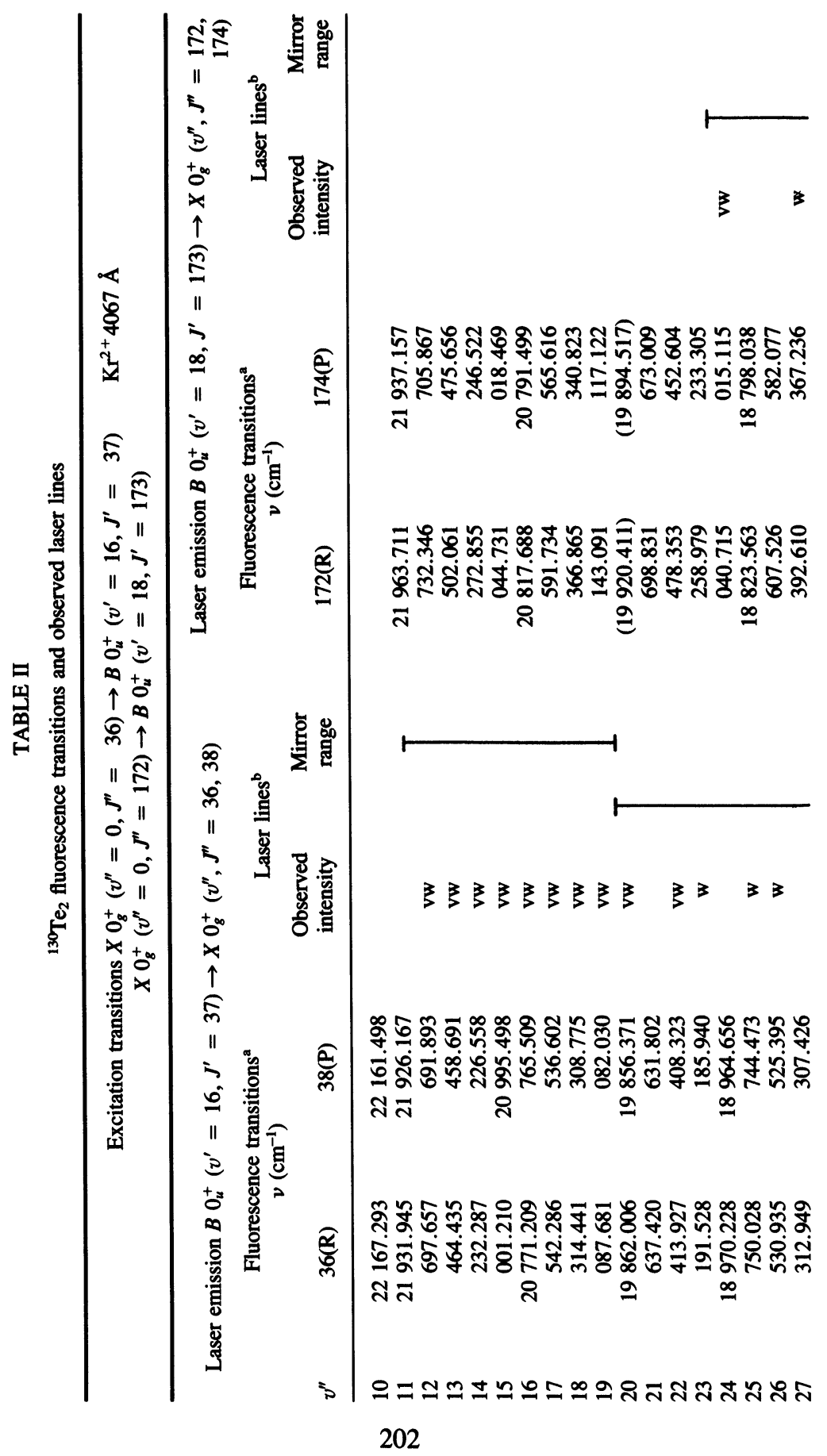




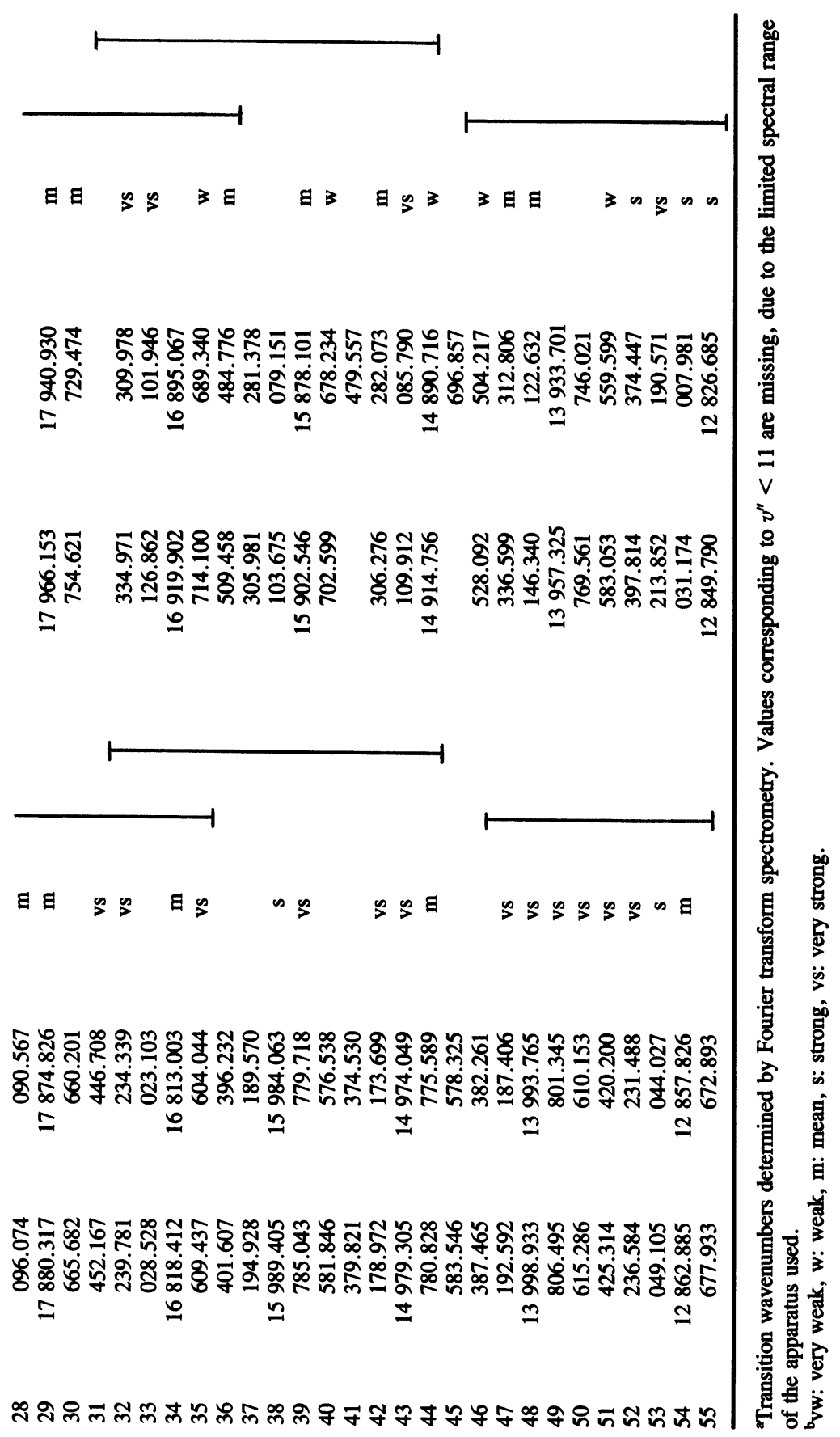




\section{TABLE III}

Fluorescence transitions and observed laser lines in natural $\mathrm{Te}_{2}$

$$
{ }^{130} \mathrm{Te}_{2} \quad \mathrm{Kr}^{2+} 4067 \AA
$$

Excitation $X 0_{8}^{+}\left(v^{\prime \prime}=0, \quad J^{\prime \prime}=36\right) \rightarrow B 0_{u}^{+}\left(v^{\prime}=16, J^{\prime}=37\right)$

Laser emission $B 0_{u}^{+}\left(v^{\prime}=16, J^{\prime}=37\right) \rightarrow X 0_{g}^{+}\left(v^{\prime \prime}, J^{\prime \prime}=36,38\right)$

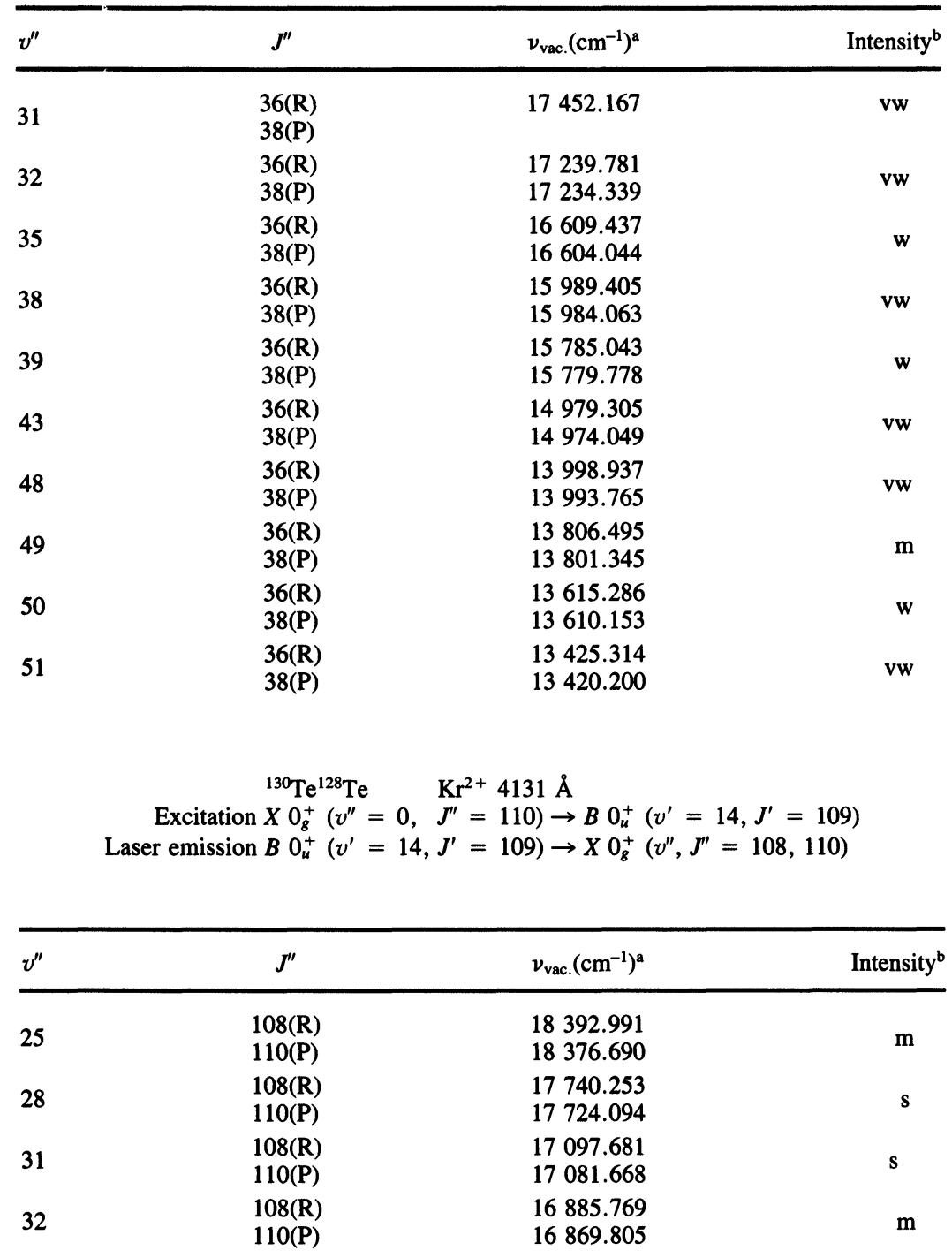


TABLE III (continued)

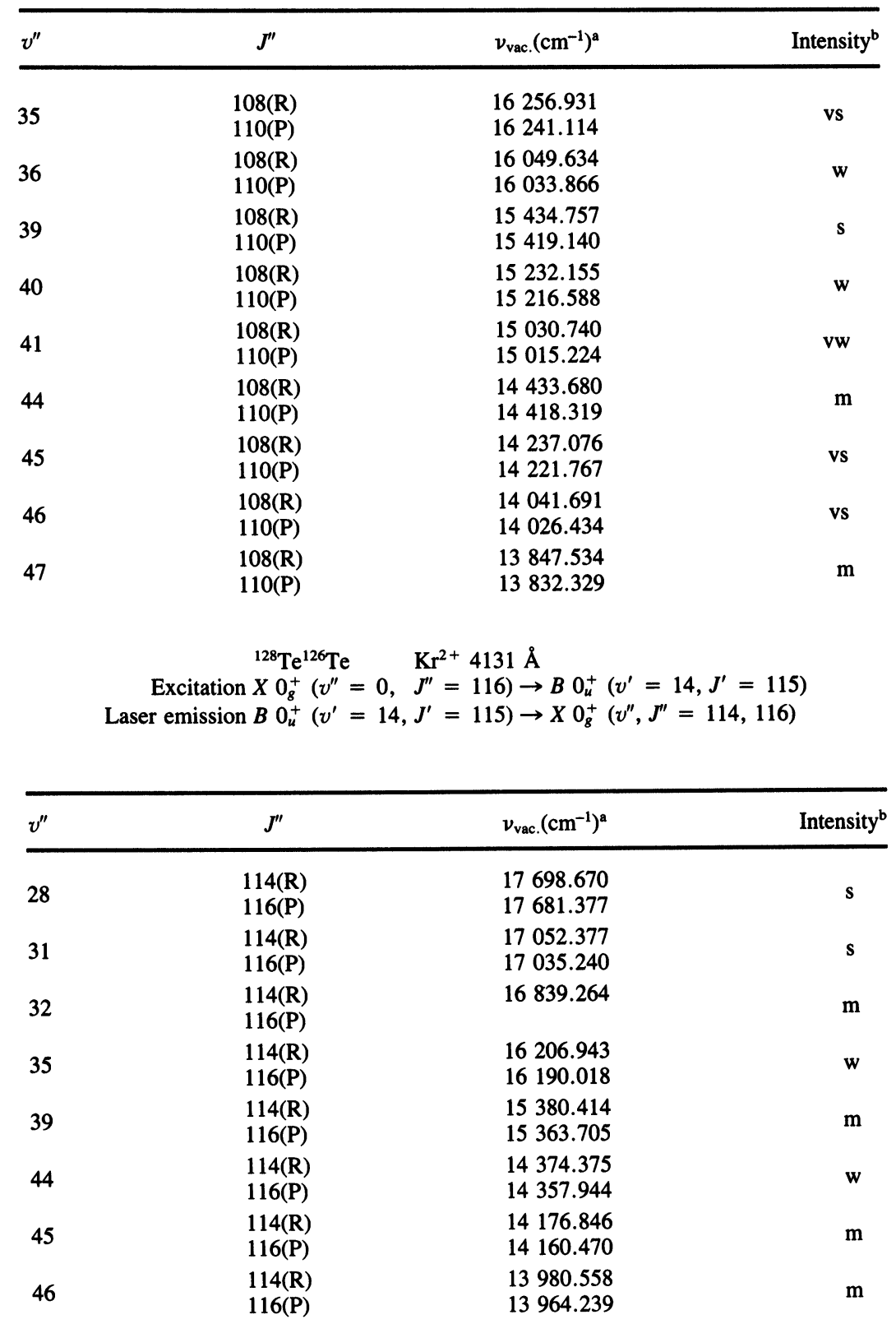


TABLE III (continued)

$$
\begin{array}{cl}
{ }^{128} \mathrm{Te}_{2} & \mathrm{Kr}^{2+} 4067 \AA \\
\text { Excitation } X 0_{g}^{+}\left(v^{\prime \prime}=0,\right. & \left.J^{\prime \prime}=56\right) \rightarrow B 0_{u}^{+}\left(v^{\prime}=16, J^{\prime}=57\right) \\
\text { Laser emission } B & 0_{u}^{+}\left(v^{\prime}=16, J^{\prime}=57\right) \rightarrow X 0_{g}^{+}\left(v^{\prime \prime}, J^{\prime \prime}=56,58\right)
\end{array}
$$

\begin{tabular}{|c|c|c|c|}
\hline$v^{\prime \prime}$ & $J^{\prime \prime}$ & $\nu_{\text {vac. }}\left(\mathrm{cm}^{-1}\right)^{\mathrm{a}}$ & Intensity ${ }^{b}$ \\
\hline 28 & $\begin{array}{l}56(\mathrm{R}) \\
58(\mathrm{P})\end{array}$ & $\begin{array}{ll}18 & 054.1 \\
18 & 045.6\end{array}$ & vw \\
\hline 31 & $\begin{array}{l}56(\mathrm{R}) \\
58(\mathrm{P})\end{array}$ & $\begin{array}{l}17406.6 \\
17398.1\end{array}$ & vw \\
\hline 35 & $\begin{array}{l}56(\mathrm{R}) \\
58(\mathrm{P})\end{array}$ & $\begin{array}{l}16559.4 \\
16551.0\end{array}$ & vw \\
\hline 38 & $\begin{array}{l}56(\mathrm{R}) \\
58(\mathrm{P})\end{array}$ & $\begin{array}{l}15936.2 \\
15927.8\end{array}$ & vw \\
\hline 39 & $\begin{array}{l}56(\mathrm{R}) \\
58(\mathrm{P})\end{array}$ & $\begin{array}{l}15730.8 \\
15722.4\end{array}$ & $v w$ \\
\hline 43 & $\begin{array}{l}56(\mathrm{R}) \\
58(\mathrm{P})\end{array}$ & $\begin{array}{l}14921.1 \\
14912.7\end{array}$ & vw \\
\hline 48 & $\begin{array}{l}56(\mathrm{R}) \\
58(\mathrm{P})\end{array}$ & $\begin{array}{l}13936.0 \\
13927.7\end{array}$ & $\mathbf{w}$ \\
\hline 49 & $\begin{array}{l}56(\mathrm{R}) \\
58(\mathrm{P})\end{array}$ & $\begin{array}{l}13742.7 \\
13734.4\end{array}$ & $\mathrm{~m}$ \\
\hline 50 & $\begin{array}{l}56(\mathrm{R}) \\
58(\mathrm{P})\end{array}$ & $\begin{array}{l}13550.6 \\
13542.3\end{array}$ & $\mathbf{w}$ \\
\hline
\end{tabular}

${ }^{a}$ Transition wavenumbers determined by Fourier transform spectrometry.

bw: very weak, w: weak, m: mean, s: strong, vs: very strong.

system can be operated with multimode and single mode excitation as well. Lowest thresholds and highest efficiencies are obtained with single mode excitation tuned exactly to resonance; however, as the single mode power of the krypton laser was only a smaller fraction of the multimode power, with multimode excitation higher output powers were obtained.

$\mathrm{The} \mathrm{Te}_{2}$ laser has also been operated with a ring resonator. For most of the lines unidirectional oscillation is obtained, as is typical for these coherently excited Raman-type dimer lasers. ${ }^{1}$ However, for some lines weak oscillation in the backward direction is also observed. Investigations of this backward oscillation have not been performed so far, but they may give some interesting information about relaxation processes and the gain contribution due to population inversion. ${ }^{1}$ 

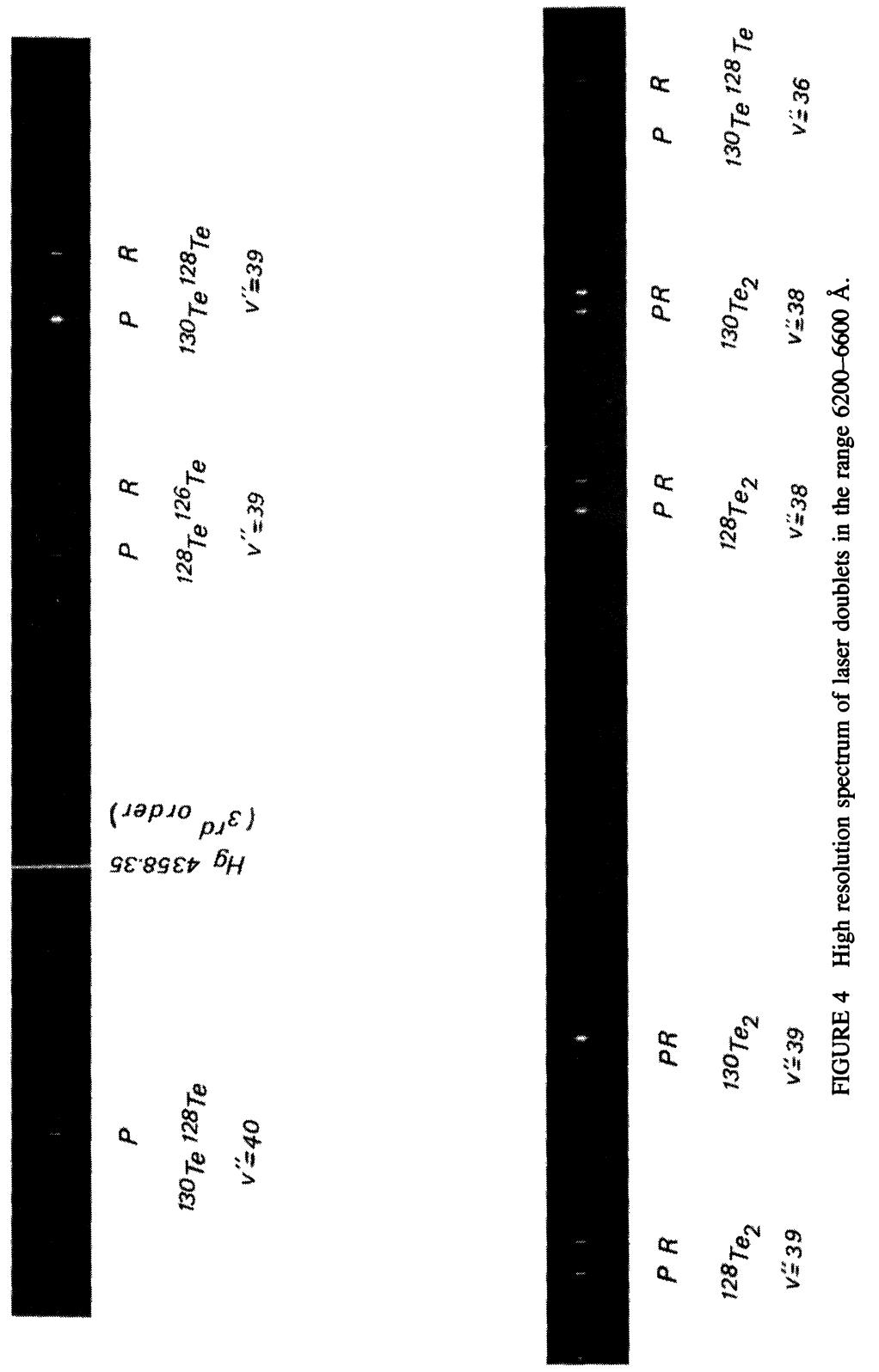
TABLE IV

Summary of $\mathrm{Te}_{2}$ laser data

\begin{tabular}{|c|c|c|}
\hline & ${ }^{130} \mathrm{Te}_{2}$ & Natural $\mathrm{Te}_{2}$ \\
\hline $\begin{array}{l}\text { Pump line } \\
\text { Laser range } \\
\text { Laser lines }\end{array}$ & $\begin{array}{l}4067 \AA \\
4600-7800 \AA \\
\sim 50 \text { doublets }\end{array}$ & $\begin{array}{r}4067 \AA \\
4131 \AA \\
5200-7500 \AA^{\mathrm{a}} \\
\sim 40 \text { doublets }\end{array}$ \\
\hline $\begin{array}{l}\text { Threshold } \\
\text { Pump power } \\
\text { (multimode) } \\
\text { Output power } \\
\text { (multiline) } \\
\text { Output power } \\
\text { (single line) } \\
\text { Gain }\end{array}$ & $\begin{array}{l}<2 \mathrm{~mW} ;<6 \mathrm{~W} \mathrm{~cm}^{-2} \\
\text { up to } 600 \mathrm{~mW} \\
\text { up to } 30 \mathrm{~mW} \\
\text { (output coupling } 4 \% \text { ) } \\
\text { up to } 10 \mathrm{~mW} \\
\sim 0.04 \mathrm{~cm}^{-1}\end{array}$ & $\begin{array}{l}<10 \mathrm{~mW} \\
\sim 1500 \mathrm{~mW} \text { (both lines) } \\
3 \mathrm{~mW} \\
\text { (output coupling <0.5\%) } \\
\quad- \\
\quad-\end{array}$ \\
\hline $\begin{array}{l}\text { Length of } \\
\text { vapor zone } \\
\text { Temperature } \\
\text { Reservoir/cell } \\
\text { Dimer } \\
\text { Pressure }\end{array}$ & $\begin{array}{l}7 \mathrm{~cm} \\
\sim 510^{\circ} \mathrm{C} / 700^{\circ} \mathrm{C} \\
\sim 2.5 \mathrm{~m} \mathrm{bar}\end{array}$ & \\
\hline
\end{tabular}

${ }^{a}$ For natural $\mathrm{Te}_{2}$ laser investigations at shorter wavelengths have not been performed.

bDetermined from maximum output coupling.

\section{CONCLUSION}

The technique of fixed-frequency laser-induced fluorescence together with high resolution Fourier transform spectrometry has enabled systematic investigations of optically pumped laser oscillation in natural tellurium and ${ }^{130} \mathrm{Te}_{2}$ dimers. So far hundreds of new laser lines in the spectral range of $4600 \AA-7800 \AA$ on the $B 0_{u}^{+} \rightarrow X 0_{g}^{+}$transition have been obtained. Taking into account Franck-Condon factors and fluorescence spectra, one can anticipate the enlargement of this spectral range in the infrared up to about $1.5 \mu$ on the $B 0_{u}^{+} \rightarrow b \Sigma_{g}^{+}$transition. At least, intense fluorescence lines on this transition have been observed. ${ }^{7}$

Furthermore, additional laser lines may be achieved by modifying the composition of natural tellurium, and it should also be possible to extend the laser range slightly towards the blue by proper operation of the laser system. Due to its dense emission spectrum, $\mathrm{Te}_{2}$ fluorescence and laser 
lines may be considered as a reference system comparable to that provided by iodine. ${ }^{9}$ Besides, the fluorescence spectra display strong relaxations, which may lead to more closely distributed collision-induced laser lines in cells containing a buffer gas. Under this aspect investigations on the $\mathrm{Te}_{2}$ system are of further actual interest.

\section{Acknowledgment}

This work was supported by C.N.R.S. through International A.T.P.

\section{References}

1. B. Wellegehausen, IEEE J. Quantum Electron. 15, 1108 (1979).

2. K. Killeen, K. Greenberg and J. T. Verdeyen, Appl. Phys. Lett. 40, 36 (1982).

3. K. Killeen, J. Epler and J. T. Verdeyen, IEEE J. Quant. Electron. to be published.

4. B. Wellegehausen, A. Topouzkhanian, C. Effantin and J. d'Incan, Opt. Commun. 41, 437 (1982).

5. B. Wellegehausen, D. Friede and G. Steger, Opt. Commun. 26, 391 (1978).

6. J. Vergès, C. Effantin, O. Babaky, J. d'Incan, S. J. Prosser and R. F. Barrow, Phys. Scripta 25, 338 (1982).

7. C. Effantin, J. d'Incan, J. Vergès, M. T. Macpherson and R. F. Barrow, Chem. Phys. Lett. 70, 560 (1980).

8. R. C. Weast, CRC Handbook of Chemistry and Physics, (CRC Press, Florida, 1979) 60th ed.

9. P. Luc and S. Gerstenkorn, Atlas du Spectre d'Absorption de la molécule d'Iode (Editions du C.N.R.S., Paris, 1978). 